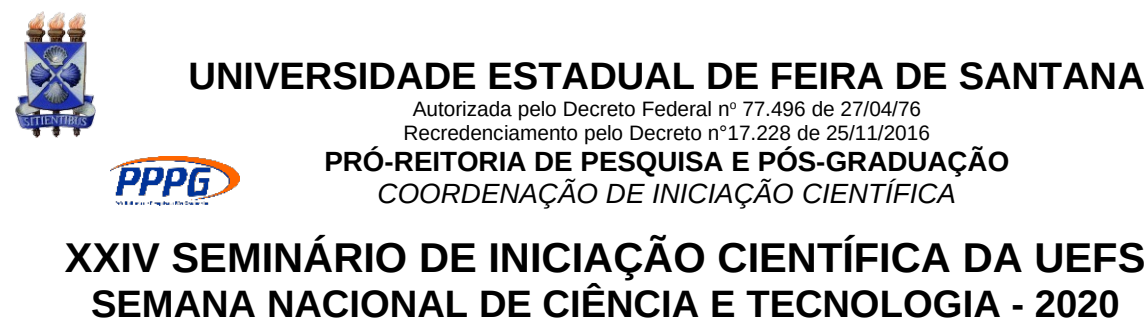

\title{
A língua tupi no semiárido baiano: heranças dialetais do povo indígena na região de Jeremoabo.
}

\author{
Saádia Ramos Ferreira ${ }_{-}^{1}$; Norma Lúcia Fernandes de Almeida ${ }^{2}$ \\ 1. Voluntária PEVIC - Graduanda em Letras Vernáculas, Universidade Estadual de Feira de Santana, e-mail: \\ saadiaferreira@live.com \\ 2. Orientador, Departamento de Letras e Artes, Universidade Estadual de Feira de Santana, e-mail: norma@uefs.br
}

PALAVRAS-CHAVE: Léxico; Tupi; Jeremoabo.

\section{INTRODUÇÃO}

O léxico pode ser conceituado, de maneira genérica, como um conjunto infinito de palavras de um determinado idioma, de um determinado dialeto. De acordo com Oliveira e Isquerdo (2001), o léxico é o conhecimento compartilhado por um grupo de falantes, forma-se no âmbito do saber vocabular de um grupo sociolinguístico cultural, além de manter uma restrita relação com a história cultural da comunidade e relacionar-se com a nomeação e com a compreensão.

O termo palavra, segundo o dicionário Aurélio, é um fonema ou grupo de fonemas com uma significação. Ela faz parte do conhecimento linguístico de todo falante. O termo lexia é amplo e significa o vocábulo ou unidade lexical. No ramo da linguística, esse termo pode ser utilizado por diferentes correntes teóricas, ou seja, diferentes correntes teóricas ou ramos da linguística podem trabalhar com a lexia, esse nível da língua, o lexical.

A região de Jeremoabo, no norte da Bahia, foi povoada originalmente por Tupinambás dos grupos Muongorus e Cariacás (PORTAL JEREMOABO, 2010). Sua população estimada em 2013 era de 41.587 habitantes. A porcentagem de população urbana, que era de apenas $12 \%$ em 1970, chegou a $40 \%$ do total do município em 1995. Pelo fato da região de Jeremoabo ter sido originalmente povoada por indígenas, acreditamos que nos dias atuais ainda podem haver muitos vestígios ou heranças desses povos naquela região, principalmente em relação ao léxico. Como o próprio nome Jeremoabo tem origem indígena, na língua tupinambá o termo significa "plantação de abóbora”.

O presente trabalho tem como objetivo pesquisar, relacionar e compreender termos usados nessa região que tenham origem Tupi. O tupi antigo era a língua falada pelas tribos de povos tupi-guarani. Dentre os grupos reconhecidos pelos historiadores, antropólogos e linguistas que tinham o tupi antigo como língua materna estão os tupinambá, os tupiniquim, os caeté, os tamoio, etc. (Sampaio, 1955). Houve em termos de herança lexical indígena no português uma "tupinização", já que o tupi serviu de base para a língua geral que era falada em comunicações interétnicas, entre outras questões.

A língua tupi antiga possui vários documentos que descrevem sua estrutura, sendo o padre jesuíta José de Anchieta considerado como seu primeiro gramático. Nos séculos XVI e XVII, era chamado pelos portugueses de "língua brasílica"[ por ser o idioma mais usado no Brasil. Os europeus que vinham viver no Brasil, bem como os escravos africanos que eram trazidos para o país, a aprendiam e falavam no seu dia a dia, usando o português apenas nas suas relações com a Coroa Portuguesa. Em 1758 o Marquês de Pombal proibiu o uso de qualquer língua indígena, com isso ela deixou foi aos poucos deixando de ser falada em 
algumas áreas urbanas. A língua geral é falada até hoje em algumas regiões do Brasil e é conhecida como nheengatu.

\section{MATERIAL E MÉTODOS OU METODOLOGIA (ou equivalente)}

As amostras analisadas fazem parte do corpus da coleção Amostras da língua falada do semi-árido baiano, organizada pelas professoras Norma Lúcia Fernandes de Almeida e Zenaide de Oliveira Novais Carneiro; a coleção é composta por quatro volumes, mas foi utililizado o Volume IV - Amostras da língua falada na zona rural de Jeremoabo (nordeste).

A metodologia utilizada foi a da sociolinguística laboviana, com gravações DID (diálogo entre informante e documentador), possui entrevistas com seis homens e seis mulhres; faixa etária: Faixa 1 - informantes entre 18-38 anos, Faixa 2 - informantes entre 3958 anos, Faixa 3 - informantes a partir de 59 anos; tendo como escolaridade até a $5^{\text {a }}$ série/ $6^{\circ}$ ano do ensino fundamental I.

Os procedimentos metodológicos foram: fazer um levantamento das ocorrências dos vocábulos de base indígena. A partir desse levantamento foram pesquisadas as suas respectivas ocorrências em dicionários, antigos e contemporâneos, principalmente no dicionário de Tupi Antigo, de Navarro (edição de 2013) e no de Carvalho (1987) com o intuito de atestar a origem da lexia e verificar os significados apresentados, comparando o significado dado na comunidade com o significado encontrado nos dicionários; realizar a elaboração dos verbetes.

\section{RESULTADOS E/OU DISCUSSÃO (ou Análise e discussão dos resultados)}

A nossa língua está em constante mudança e com essas mudanças sempre estão surgindo inúmeras palavras novas, ou até mesmo o aperfeiçoamento de palavras já existentes. "Os sistemas semióticos, particularmente o linguístico, caracterizam-se por um permanente nascer de signos. Esse contínuo enriquecimento atende a uma exigência do meio social, que está em constante transformação" (BARBOSA, 2001, p.35).

A principal função da língua é ser instrumento de comunicação e interação social. Ela está em constante transformação, porém, essas transformações não a impossibilita de realizar suas funções. As transformações da língua são provocadas por influências de natureza geográfica, sociocultural e histórica. "A língua entendida como organismo vivo transforma-se sem parar, e estas transformações são explicadas no próprio funcionamento da língua" (OLIVEIRA, 2001, p. 109), por menor que seja o espaço geográfico onde uma determinada língua é utilizada, não impede a sua contínua transformação.

Segundo Biderman (2001, p. 14), “o léxico de uma língua natural pode ser identificado com o patrimônio vocabular de uma dada comunidade linguística ao longo de sua história. Assim, para as línguas de civilização, esse patrimônio constitui um tesouro cultural abstrato, ou seja, uma herança de signos lexicais herdados e de uma série de modelos categoriais para gerar novas palavras”.

Para realizar a pesquisa lexicográfica, que é objetivo desse trabalho, é preciso, antes de tudo, pesquisar sobre a história da região a ser estudada, no caso, Jeremoabo. Pesquisar sobre os antecessores dos habitantes naturais da cidade, sobre como a cidade foi fundada, para realizar a coleta dos dados que serão necessários para o desenvolvimento desse trabalho. Isquerdo (2001) ressalta que "investigar uma língua é investigar também a cultura, considerando-se que o sistema linguístico, nomeadamente o nível lexical, armazena e acumula as aquisições culturais representativas de uma sociedade”. Esse conhecimento sobre a cultura da sociedade a ser investigada, pode trazer esclarecimentos sobre a visão de mundo e o modo de vida daquela comunidade, pois, "na formação de uma língua é preciso considerar a influência exercida pelo ambiente através da experiência social” (OLIVEIRA, 2001, p.109).

Para realizar o estudo da linguagem dentro do universo cultural, os estudiosos se baseiam no campo da antropologia. Especificamente, em um estudo conhecido como 
Antropologia Linguística, onde apresenta-se a linguagem como prática cultural. Para explicar esse processo, Seabra (2015) cita as "teorias da cultura" desenvolvidas por Duranti (2000), baseadas na antropologia contemporânea. Dentre essas teorias, destacam-se: a cultura como algo distinto da natureza; a cultura como conhecimento; a cultura como comunicação; a cultura como um sistema de mediação; a cultura como um sistema de práticas; a cultura como um sistema de participação.

O município de Jeremoabo fica localizado ao norte do Estado da Bahia, próximo ao município de Paulo Afonso. No ano de 2013, sua população era estimada em 41.587 habitantes. A região de Jeremoabo foi originalmente povoada por povos Tupinambás dos grupos Muongorus e Cariacás. O nome Jeremoabo tem origem na língua Tupi, onde significa, entre outras coisas, “plantação de jerimum” (Portal do Jeremoabo, 2010).

Devido à grande expansão territorial de Jeremoabo, várias povoações, mais comumente as antigas aldeias indígenas, desvincularam-se da cidade original e partiram para outros territórios, assim constituindo, após um tempo, novos municípios.

A tabela a seguir apresenta os termos que possuem origem indígena, que foram encontrados a partir das entrevistas que compõem a coleção Amostras da Língua Falada na Zona Rural de Jeremoabo. Na primeira parte, de termos encontrados, apresenta-se o termo exatamente como foi encontrado nas entrevistas e entre parênteses a escrita conforme à norma culta. Logo em seguida está o termo na língua tupi, retirados do Dicionário de Tupi (antigo) Português de Moacyr Ribeiro de Carvalho. Por fim, apresenta-se os significados retirados do Dicionário Aurélio e do Dicionário Online de Português.

\begin{tabular}{|c|c|c|c|}
\hline $\begin{array}{c}\text { TERMO } \\
\text { ENCONTRADO }\end{array}$ & TUPI & $\begin{array}{c}\text { SIGNIFICADO (dicio. } \\
\text { Aurelio) }\end{array}$ & SIGNIFICADO (dicio. Online) \\
\hline Mandioca & MANDI-OKA & $\begin{array}{l}\text { Planta euforbiácea de } \\
\text { tubérculos alimentícios } \\
\text { que servem para fazer } \\
\text { farinha de mesa, etc.; há } \\
\text { também respécies } \\
\text { venenosas. }\end{array}$ & $\begin{array}{l}\text { Gênero de plantas euforbiáceas, que } \\
\text { compreende arbustos da América, } \\
\text { cuja raiz fornece uma fécula } \\
\text { nutritiva, de que se faz a tapioca. }\end{array}$ \\
\hline Caçano (caçando) & ÇÔ- KAÂ-BO & Busca, perseguição. & $\begin{array}{l}\text { Perseguir; seguir animais silvestres } \\
\text { para os prender; matar animais } \\
\text { silvestres: o caçador foi preso por } \\
\text { caçar animais em extinção. }\end{array}$ \\
\hline Tatu-peba & TATU-PEWA & $\begin{array}{l}\text { Tatu de pelagem densa; } \\
\text { tatu-peludo. }\end{array}$ & $\begin{array}{l}\text { Peba; tatu amarronzado cuja } \\
\text { carapaça contém poucos pelos, com } \\
\text { seis ou oito cintas de placas móveis, } \\
\text { sendo sua cabeça achatada em } \\
\text { formato cônico. }\end{array}$ \\
\hline $\begin{array}{c}\text { Arapuca } \\
\text { (=armadilha) }\end{array}$ & ARATAKA & $\begin{array}{l}\text { Armadilha para apanhar } \\
\text { passarinhos. }\end{array}$ & $\begin{array}{l}\text { Armadilha feita de pauzinhos para } \\
\text { apanhar pássaros. }\end{array}$ \\
\hline Tatu & TATU & $\begin{array}{l}\text { Nome comum aos } \\
\text { dasipodídeos. }\end{array}$ & $\begin{array}{l}\text { Coberta; abrigo contra a chuva, feita } \\
\text { de talos e folhas. Carne do músculo } \\
\text { da perna da rês. }\end{array}$ \\
\hline Caititu & TAITETU & $\begin{array}{l}\text { Mamífero taiaçuídeo da } \\
\text { América do Sul, tb. } \\
\text { Chamado, impr., porco- } \\
\text { do-mato. }\end{array}$ & $\begin{array}{l}\text { Mamífero paquiderme, espécie de } \\
\text { porco do mato, também chamado } \\
\text { queixada. Cilindro do aparelho de } \\
\text { ralar mandioca. }\end{array}$ \\
\hline Cutia & AKÔ-TI & $\begin{array}{l}\text { Mamífero dasiproctídeo } \\
\text { que habita matas e } \\
\text { capoeiras. }\end{array}$ & $\begin{array}{l}\text { Animal que se parece com o coelho } \\
\text { e tem costumes um tanto } \\
\text { semelhantes aos deste. }\end{array}$ \\
\hline $\begin{array}{c}\text { Caibera } \\
\text { (craibeira/ipê) }\end{array}$ & Y'-PÉ & $\begin{array}{l}\text { Nome comum às árvores } \\
\text { bignoniáceas, } \\
\text { ornamentais, de madeira } \\
\text { útil, com flores amarelas, } \\
\text { brancas, arroxeadas ou }\end{array}$ & $\begin{array}{l}\text { Nome dado a várias árvores } \\
\text { bignoniáceas conhecidas } \\
\text { beleza de suas flores. }\end{array}$ \\
\hline
\end{tabular}




\begin{tabular}{|c|l|l|l|}
\hline $\begin{array}{c}\text { Mancambira } \\
\text { (macambira) }\end{array}$ & MAKAMBÍRA & róseas. & \\
& & & $\begin{array}{l}\text { Planta da família das Bromeliáceas } \\
\text { (Bromelia laciniosa), encontrada } \\
\text { nas regiões mais quentes e secas das } \\
\text { caatingas brasileiras, cujos rizomas } \\
\text { e raízes, muito ramificados, cobrem, } \\
\text { juntamente com as folhas grandes } \\
\text { de bordos espinhosos, extensas } \\
\text { áreas. }\end{array}$ \\
\hline $\begin{array}{c}\text { Jirimum } \\
\text { (jerimum) }\end{array}$ & ÎURU-MŨ & Abóbora. & $\begin{array}{l}\text { Abóbora, fruto da aboboreira, ou } \\
\text { jerimunzeiro, de polpa alaranjada, } \\
\text { sendo largamente utilizado em } \\
\text { variados pratos culinários, doces ou } \\
\text { salgados. }\end{array}$ \\
\hline
\end{tabular}

\section{CONSIDERAÇÕES FINAIS (ou Conclusão)}

Sabe-se que o léxico de uma língua demonstra a realidade da cultura de um povo e, além disso, carrega a história de uma sociedade. Segundo Oliveira e Isquerdo (2001) "o léxico de uma língua conserva uma estreita relação com a história cultural da comunidade”. No caso do Português Brasileiro (PB), houve influências das línguas indígenas, como foi abordado neste trabalho, e das línguas africanas. Influências essas que se deram devido à colonização do Brasil pelos portugueses. Portanto, é importante conscientizar-se sobre quem foram os primeiros habitantes desse país e como, apesar de tantas transformações ao longo do tempo, ainda se encontra grandes vestígios e influências da língua desses povos no léxico atual.

\section{REFERÊNCIAS}

ALMEIDA, Norma Lucia F. de e CARNEIRO, Zenaide de O. N. Amostras da língua falada no semi-árido baiano. Feira de Santana, UEFS/FAPESB.

BARBOSA, L. (2009). O conceito de lexicultura e suas implicações para o ensinoaprendizagem de português língua estrangeira. Filologia E Linguística Portuguesa, 31-41. Disponível em <https://doi.org/10.11606/issn.2176-9419.v0i10-11p31-41>. Acesso em 15 de março de 2019.

CUNHA, Manuela Carneiro da (org.). 1992. História dos índios no Brasil. São Paulo: Companhia das Letras, Secretaria Municipal de Cultura, FAPESP. Disponível em <http://www.etnolinguistica.org/historia>. Acesso em 15 de março de 2019.

OLIVEIRA, Ana Maria Pinto Pires de; ISQUERDO, Aparecida Negri. 2001. As ciências do léxico: lexicologia, lexicografia e terminologia. 2 ed. Campo Grande, MS: ED. UFMS.

SEABRA, Maria Cândida Trindade Costa de; "Língua, Cultura, Léxico", p. 65-84 . In: Sobral, Gilberto Nazareno Telles; Lopes, Norma da Silva; Ramos, Jânia Martins. 2015. Linguagem, Sociedade e Discurso. São Paulo: Blucher.

SAMPAIO, Theodoro. 1955. O Tupi na geografia nacional. Salvador: Câmara Municipal de Salvador.

Portal Jeremoabo. Disponível em < $\underline{\text { http://blogportaljeremoabo.blogspot.com.br/p/historia-da- }}$ cidade.html>. Acesso em 14 de março de 2019.

HISTÓRIA. Portal da Prefeitura Municipal de Jeremoabo, JEREMOABO, 2012. Disponível em: http://www.jeremoabo.ba.io.org.br/historia. Acesso em: 23/07/2020.

CARVALHO, Moacyr Ribeiro de. 1987. Dicionário Tupi (antigo) português. In.: http://etnolinguistica.wdfiles.com/local--files/biblio\%3Acarvalho-1987-dicionario/

Carvalho 1987 DicTupiAntigo-Port OCR.pdf.

FERREIRA, Aurélio Buarque de Holanda. 2008. Miniaurélio: o minidicionário da língua portuguesa dicionário/ Aurélio Buarque de Holanda Ferreira; coordenação de edição Marina Baird Ferreira; equipe de lexicografia Margarida dos Anjos. - 7. Ed. - Curitiba: Ed. Positivo.

Dicionário Online de Português. Dicio, 2009. Encontrado em: https://www.dicio.com.br/. Acesso em: 21/07/2020. 